https://doi.org/10.48009/1_iis_2006_98-101

\title{
TEACHING UML DATABASE MODELING TO VISUALLY IMPAIRED STUDENTS
}

\author{
Robert G. Brookshire, University of South Carolina, brookshire@sc.edu
}

\begin{abstract}
Teaching visual diagramming techniques such as the UML class diagram is an important part of database modeling instruction. Visually impaired students, however, have difficulty using software tools such as Microsoft Visio ${ }^{\circledR}$, as the tools do not work well with screen reading software. This paper describes a simple method that allows visually impaired students to create class diagrams. An advantage of this method is that it is readily usable by sighted students, so that the visually impaired may work on teams with sighted students.
\end{abstract}

Keywords: Visually Impaired, UML, Database Design, Class Diagram

"From the point of view of a computer, all human users are handicapped" [17, p. 143].

\section{INTRODUCTION}

Almost since the advent of information systems, diagramming techniques have been used to model them [11]. The entity-relationship diagram [5] has been the most widely used for modeling database systems, with its many variations [23]. The Unified Modeling Language (UML)[21], a set of diagramming techniques for modeling all aspects of information systems, is becoming an industry standard [19]. The specific UML diagram used to model databases is the class diagram.

Teaching students to develop class diagrams, or the similar ERD, is a fundamental component of database instruction. As Bock and Yaeger note, "One of the interesting challenges for database instructors is the task of teaching novice students how to achieve accuracy during the development of data models" [3]. This is especially challenging if the students are visually impaired.

The pervasiveness of the graphical user interface (GUI) has made using the computer much more difficult for the visually impaired [20, 10, 12]. Diagrams, or graphs [4], on computers are especially demanding [13]. As Donker, Klante, and Gorny [7] explain, there are several barriers to use. The pixel barrier results because the pixels comprising the image are not readable by screen reading software.
The mouse barrier arises because the visually impaired cannot manipulate pointing devices effectively. The graphics barrier comes about because transforming images to other media always means a loss of information. Finally, the layout barrier occurs when important information is conveyed by the location of images on the screen $[7,12,13,15]$.

Researchers have developed many different systems for conveying graphical information to visually impaired computer users. These fall into two categories, auditory, in which sound is used to enhance the interface $[1,2,4,6,7,14,18,25]$, and tactile or haptic, using a touch-based system [15, 24]. Some designers have attempted to combine these methods [14]. These systems are mostly experimental, however, and many rely on specialized hardware or software, or require training to use.

\section{THE CHALLENGE}

In the fall of 2005, a visually impaired student enrolled in the introductory database course in our curriculum. I knew, therefore, that it was likely he would be enrolled in my intermediate courses in the spring of 2006. The student, 34 years old, had been blind for 14 years, and had only some light perception. He was not able to read or see diagrams on the computer display. He used the computer with the JAWS screen reading software [9]. I was immediately concerned that the diagramming software used in the intermediate course, Microsoft Visio®, might not be compatible with the JAWS software used by our student and available in our computer labs.

The student came to see me during the fall to find out what text I would be using in the course. This would enable him to obtain an audio version of the text before the semester began. I asked the student to test both the Oracle database software and the Visio software for compatibility with JAWS. Oracle presented no problems with JAWS, in either the characterbased or web interface versions. Visio, however, was a problem. The best that JAWS could do with Visio diagrams was to read "Diagram 1," "Diagram 2," and so on. I therefore determined to design a diagramming method that the student could use to learn to construct class diagrams without the use of diagramming software. 
The objectives in designing the method were that the system be intuitively easy to use, suitable for both blind and sighted students, and that the system would allow the visually impaired student to be a creator of the diagrams himself $[6,8]$. I decided to use a tactile method, rather than an auditory one. Sighted students get an overall view of a diagram, something that is not present with an auditory rendering [13]. A tactile method for diagram creation more nearly approximates the sighted student's experience [22].

\section{THE DESIGN}

As with most powerful diagramming techniques, the class diagram is composed of just a few elements. The critical elements are rectangles, to indicate classes, lines, to indicate relationship, and symbols that designate the cardinality of the relationships between the classes. The attributes of the classes, which correspond to the fields in the database tables, are composed of text and can be entered separately in a word processor or text editor. Figure 1 shows an example database design composed of class diagrams [16].

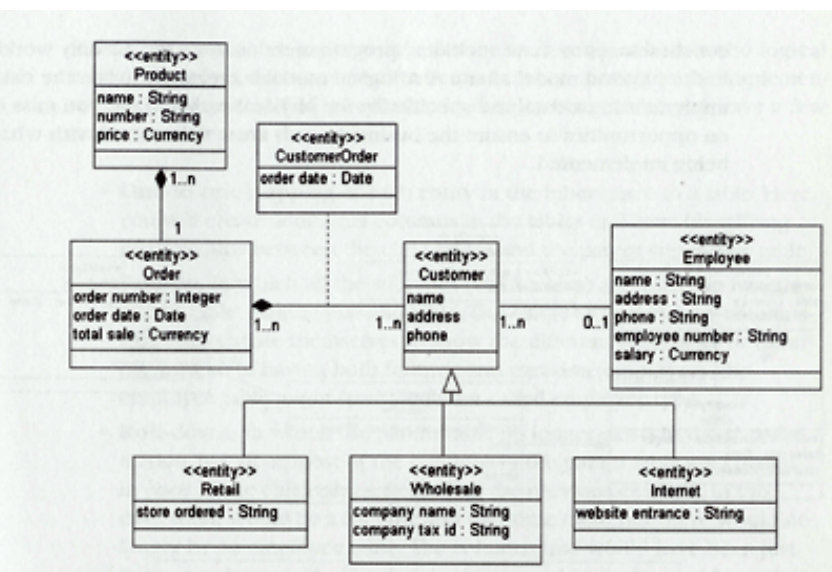

Figure 1. Example Class Diagram [16, p. 157]

I started with three-by-five inch $(10.1 \mathrm{~cm}$ by $15.3 \mathrm{~cm})$ cards to furnish the rectangles for the classes. I rejected the idea of using string to represent the lines connecting the classes, as strings would require some sort of physical anchoring system on each end to remain straight. I chose instead thin plastic strips cut from the binding of the boxes used to deliver copier paper. The strips are about $1 / 4$ inch $(6 \mathrm{~mm})$ wide, making them easy to manipulate. I cut them into lengths of about one foot $(30.5 \mathrm{~cm})$. Flat thumbtacks were used to fasten the strips to the mounting surface.

I decided initially to use a large sheet of cardboard as the surface on which the diagram was to be mounted. The sheet was approximately 25.5 inches $(64.5 \mathrm{~cm})$ by 20 inches $(50.5 \mathrm{~cm})$ and about $1 / 8$ inch $(3 \mathrm{~mm})$ thick.

Pushpins were used to represent cardinality. The student was instructed to mount a set of pushpins at each end of the strip connecting two classes. Pins on one side of the strip represented the minimum cardinality, and pins on the other side represented the maximum. No pin represented zero, one pin represented one, and two pins represented many. A one-to-many relationship had one pin on one side of the strip and two pins on the other; a zero or one relationship had no pins on one side and one on the other.

\section{TESTING THE DESIGN}

On the first day that we discussed class diagrams in the course, I assigned the students to work in pairs to construct a database model using class diagrams. I spent a few minutes orienting the visually impaired student and his sighted partner on the use of the cards, pushpins, and plastic strips, and how they corresponded to the elements of the diagram. The sighted student was instructed to create a Visio diagram that matched the physical diagram the pair constructed together. This was so the sighted student would get experience with the software.

The visually impaired student used Microsoft Word to enter the attributes of the classes. He was very familiar with this software, so this presented no barrier to him. Sighted students entered the class attributes directly on the class diagrams themselves. The pair was able to create an appropriate diagram in their first attempt. We discovered, however, that the cardboard surface for the diagram was inadequate-it was too thin, so that the pushpins and thumbtacks pierced completely through the board, leaving their points projecting from the back of the cardboard.

At the next class meeting, I brought a cardboard box about the width and length of the previous cardboard sheet, but $1 \frac{1}{4}$ inches $(32 \mathrm{~mm})$ thick. This provided a surface into which the thumbtacks and pushpins could penetrate without going through to the other side. In this class period, students again worked in pairs to create a different database model.

As an out-of-class assignment, students were instructed to create a database model based on a set of requirements presented in class. Sighted students worked individually using the Visio software. They could work either at home or in the computer lab. The visually impaired student came to my office where he collected the diagramming materials. He 
then worked independently in a conference room next door to complete the assignment.

\section{ASSESSMENT}

The quality of the database diagrams created by the visually impaired student was similar to the quality of the diagrams created by the sighted students using Visio. While none of the diagrams he created was perfect, the kinds of errors he made were similar to the errors made by other students. These were exclusively logic errors, and did not depend on the medium used to create the diagrams.

In the student's evaluation of the diagramming system, he said that he appreciated the tactile nature of the tool. He found this superior to the auditory graphics systems he had used in the past.

\section{CONCLUSION}

This paper has described a simple method that allows visually impaired students to create class diagrams. This method would be easily extended to entityrelationship diagrams, as well. The method is easy to use, easy to learn, and can be employed by both sighted and blind students, so that they can work in teams. As a tactile system, it is superior to auditory systems that do not give users an overall view of the diagram being created.

\section{REFERENCES}

1. Alty, J. L. \& Rigas, D. I. (1998). Communicating Graphical Information to Blind Users Using Music: The Role of Context, Proceedings of the SIGCHI conference on Human factors in computing systems, Los Angeles, CA, USA, 574-581.

2. Armaly, A. (2005). Making Linux Accessible For the Visually Impaired With Speakup. Linux Journal, 2005(140), 6.

3. Bock, D. B. and Yaeger, S. E. (2002). Improving Entity Relationship Modeling Accuracy with Novice Data Modelers. Journal of Computer Information Systems 42(2), 69-75.

4. Brown, A., Pettifer, S. \& Stevens, R. (2003). Evaluation of a NonVisual Molecule Browser. Proceedings of the 6th international ACM SIGACCESS conference on Computers and accessibility, Atlanta, GA, USA, $40-47$.

5. Chen, P. P. (1976). The Entity-Relationship Model: Toward a Unified View of Data," $A C M$ Transactions on Database Systems, 1(1), 9-36.

6. Cohen, R. F., Meacham, A., \& Skaff, J. (2006). Teaching Graphs to Visually Impaired Students
Using an Active Auditory Interface, Proceedings of the 37th SIGCSE technical symposium on Computer science education, Houston, TX, USA, 279-282.

7. Donker, H., Klante, P. \& Gorny, P. (2002) The Design of Auditory User Interfaces for Blind Users, Proceedings of the second Nordic conference on Human-computer interaction, Arhus, Denmark, 149-156.

8. Edwards, K., Mynatt, E. \& Stockton, K. ( 1995). Access for Blind Users. Interactions, 2(1), 5467.

9. Freedom Scientific, Inc. (2006). JAWS for Windows. http://www. freedomscientific.com/ fs_products/ JAWS_HQ.asp

10. Hampel, T., Reinhard Keil-Slawik, R., Claassen, B. G., Plohmann, F. \& Reimann, C. (1999). Pragmatic Solutions for Better Integration of the Visually Impaired in Virtual Communities, Proceedings of the international ACM SIGGROUP conference on Supporting group work, Phoenix, AZ, USA, 258-266.

11. Jones, R. A., Tsay, J. J. \& Griggs, K. (2006). An Empirical Investigation of the Task Specific Relative Strengths of Selected Accounting and Information Systems Diagramming Techniques. Journal of Computer Information Systems, 46(4), 99-114.

12. Kamel, H. M. \& Landay, J. A. (2000). A Study of Blind Drawing Practice: Creating Graphical Information without the Visual Channel. Proceedings of the fourth international ACM conference on Assistive technologies Arlington, VA USA, 34-41.

13. Kamel, H. M. \& Landay, J. A. (2002). Sketching images eyes-free: a grid-based dynamic drawing tool for the blind, Proceedings of the fifth international ACM conference on Assistive technologies Edinburgh, Scotland, 33 - 40.

14. Kennel, A. R. (1996). AudioGraf: A DiagramReader for the Blind, Proceedings of the second annual ACM conference on Assistive technologies, Vancouver, British Columbia, Canada, 51-56.

15. Kurze, M. (1996) TDraw: A Computer-based Tactile Drawing Tool for Blind People, Proceedings of the second annual ACM conference on Assistive technologies, Vancouver, British Columbia, Canada, 131-138.

16. Maksimchuk, R. A. \& Naiburg, E. J. (2005). UML for Mere Mortals. Boston, MA: Addison Wesley.

17. McMillan, W. W. (1992). Computing for Users with Special Needs and Models of ComputerHuman Interaction, Proceedings of the SIGCHI 
conference on Human factors in computing systems, Monterey, CA, USA, 143-148.

18. Mereu, S. W. \& Kazman, R. (1996). Audio Enhanced 3D Interfaces for Visually Impaired Users. Proceedings of the SIGCHI conference on Human factors in computing systems: common ground, Vancouver, BC, Canada, 72-78.

19. Mrdalj, S. \& Jovanovic, V. (2004). UML Coverage in Systems Analysis and Design Textbooks. Issues in Information Systems, 5(1), 233-239.

20. Mynatt, E. D. and Edwards, W. K. (1992). Mapping GUIS to Auditory Interfaces, Proceedings of the 5th annual ACM symposium on User interface software and technology, Monterey, CA, USA, 61-70.

21. Object Management Group (2006). Unified Modeling Language (UML), version 2.0. http://www.omg.org/ technology/documents/formal/ uml.htm
22. Petrie, H., Morley, S., \& Weber, G. (1995). Tactile-based direct manipulation in GUIs for blind users, Conference companion on Human factors in computing systems, Denver, CO, USA, 428-429.

23. Pons, A. P, Polak, P. \& Stutz, J. (2006). Evaluating the Teaching Effectiveness of Various Data Modeling Notations. Journal of Computer Information Systems, 46(2), 78-84.

24. Rotard, M., Knödler, S. \& Ertl, T. (2005) A Tactile Web Browser for the Visually Disabled. Proceedings of the sixteenth ACM conference on Hypertext and hypermedia, Salzburg, Austria, 15-22.

25. Vickers, P. \& Alty, J. L. (2005). Musical Program Auralization: Empirical Studies. ACM Trans-actions on Applied Perception, 2(4), 47748. 